See Article page 75 .

\section{Commentary: MANTA could be an ace in the hole for peripheral extracorporeal membrane oxygenation}

\author{
David L. Joyce, MD, MBA
}

The University of Maryland Medical Center Extracorporeal Membrane Oxygenation (ECMO) group is to be congratulated for their innovation in tackling one of the most annoying problems encountered in the patient with cardiopulmonary failure. ${ }^{1}$ At the risk of ignoring the insights from Tversky and Kahneman in their 1971 manuscript on "Belief in the Law of Small Numbers," I would propose that deploying the MANTA (Teleflex, Morrisville, NC) in the ex post management of percutaneous cannulation represents a promising strategy for future study. As we celebrate the use of this beautiful new mouse trap, I think it is important to consider the question of how we found ourselves with a rodent infestation in the first place. Perhaps another way to tackle the problem of large holes in the femoral artery is to prevent them from being made in the first place.

$\mathrm{Shah}^{3}$ has made a compelling argument for the importance of sending cardiothoracic surgeons to the front lines of the shock practice, even in the setting of "mobile ECMO." While it is certainly the case that there are some very gifted critical care and emergency medicine specialists who can safely deploy large cannulae into the groin vessels, this is a practice that can often be avoided altogether. The challenge that surgeons have historically faced with early referral of candidates for durable left ventricular assist

From the Department of Surgery, Medical College of Wisconsin, Milwaukee, Wis. Disclosures: The author serves as a consultant for Abiomed and is a member of the TandemHeart Experiences and Methods (THEME) steering committee for LivaNova.

The Journal policy requires editors and reviewers to disclose conflicts of interest and to decline handling or reviewing manuscripts for which they may have a conflict of interest. The editors and reviewers of this article have no conflicts of interest.

Received for publication Nov 19, 2020; revisions received Nov 19, 2020; accepted for publication Nov 26, 2020; available ahead of print Dec 7, 2020.

Address for reprints: David L. Joyce, MD, MBA, Department of Surgery, Medical College of Wisconsin, 8701 Watertown Plank Rd, Milwaukee, WI 53226

(E-mail: djoyce@mcw.edu).

JTCVS Techniques 2021;6:82-3

2666-2507

Copyright (c) 2020 The Authors. Published by Elsevier Inc. on behalf of The American Association for Thoracic Surgery. This is an open access article under the CC BY-NCND license (http://creativecommons.org/licenses/by-nc-nd/4.0/).

https://doi.org/10.1016/j.xjtc.2020.11.035

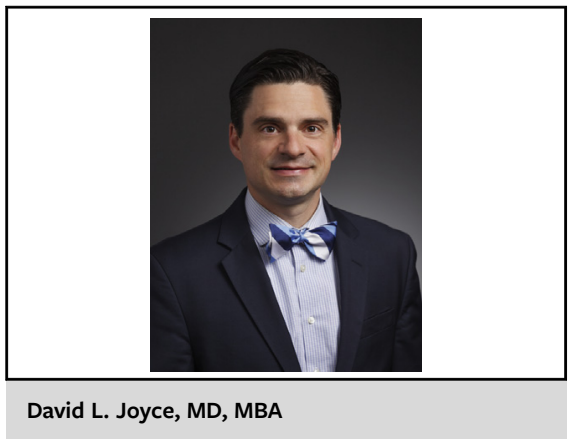

CENTRAL MESSAGE

The MANTA closure device offers another option in the myriad of strategies to improve ECMO outcomes.

device therapy seems to have metastasized to the shortterm mechanical circulatory support practice that is now gaining considerable momentum. That said, in the absence of ongoing cardiopulmonary resuscitation, our group has transitioned our approach to supporting the failing organs individually rather than through the "one size fits all" model of peripheral venoarterial ECMO. Insertion of an Impella 5.5 device (Abiomed, Danvers, Mass) through the axillary artery offers an immediate solution to the most common scenario (isolated left ventricular failure) while at the same time leaving open the possibility for right ventricular support through placement of a ProtekDuo cannula (LivaNova PLC, London, England) in the right internal jugular vein. In the rare case where gas exchange is also a problem, an oxygenator can easily be added to the circuit. This approach allows for recovery to occur in a stepwise fashion as opposed to the abrupt transition that often occurs with separation from venoarterial ECMO. Given that all of the support devices are placed above the diaphragm, patients can ambulate and participate in physical therapy. To date, our lowerextremity malperfusion rate is $0 \%$ with this approach.

Considering the fact that our specialty still debates such fundamental questions as whether or not to use the heartlung machine in an operation that was first performed in $1967,{ }^{4}$ it seems likely that there will continue to be many different philosophies on when to initiate short-term mechanical circulatory support, which devices to use, where to insert them, and ultimately how to remove them when the patient recovers. Provided that these conversations are led by cardiothoracic surgeons, it will continue to be an exciting journey. 


\section{References}

1. Shah A, Ghoreishi M, Taylor BS, Toursavadkohi S, Kaczorowski DJ, the University of Maryland Medical Center Extracorporeal Membrane Oxygenation (UMMC ECMO) Group. Complete percutaneous decannulation from femoral venoarterial extracorporeal membrane oxygenation. J Thorac Cardiovasc Surg Tech. 2021;6:75-81.
2. Tversky A, Kahneman D. Belief in the law of small numbers. Psychol Bull. 1971; 76:105-10.

3. Shah AS. Mobile extracorporeal membrane oxygenation: lead, follow, or get out of the way. J Thorac Cardiovasc Surg. 2017;153:1369-70.

4. Gaudino M, Lamy A, Shroyer AL. Commentary: trials of off- versus on-pump bypass surgery: 105 and counting. J Thorac Cardiovasc Surg. 2021;161:1283-4. 